\title{
Freeze-Fracture and Morphometric Analysis of Occluding Junctions in Rectal Glands of Elasmobranch Fish
}

\author{
Stephen A. Ernst, Seth R. Hootman, James H. Schreiber, and Clara V. Riddle \\ Department of Anatomy, University of Michigan, Medical Sciences II, Ann Arbor, Michigan 48109
}

Summary. The structure of occluding junctions in secretory and ductal epithelium of salt-secreting rectal glands from two species of elasmobranch fish, the spiny dogfish Squalus acanthias and the stingray $D a-$ syatis sabina, was examined by thin-section and freeze-fracture electron microscopy. In both species, occluding junctions between secretory cells are shallow in their apical to basal extent and are characterized by closely juxtaposed parallel strands. Average strand number in the dogfish was $3.5 \pm 0.2$ with a mean depth of $56 \pm 5 \mathrm{~nm}$; in the stingray a mean of $2.0 \pm 0.2$ strands encompassed an average depth of $18 \pm 3 \mathrm{~nm}$. In contrast, the linear extent of these junctions was remarkably large due to the intermeshing of the narrow apices of the secretory cells to form the tubular lumen. Morphometric analysis gave values of $66.8 \pm 2.5$ and $74.9 \pm 4.6 \mathrm{~m} / \mathrm{cm}^{2}$ for the length of junction per unit of luminal surface area in the dogfish and stingray, respectively. This junctional morphology is similar to that generally described for "leaky" epithelia. In comparison, the stratified ductal epithelium which carries the $\mathrm{NaCl}$-rich secretion to the intestine is characterized by extensive occluding junctions which extend $0.6-0.8 \mu \mathrm{m}$ in depth and consist of a mean of 12 strands arranged in an anastomosing network, an architectural pattern typical of "tight" epithelia. The length density of these junctions in the dogfish rectal gland was $7.6 \pm 0.1 \mathrm{~m} /$ $\mathrm{cm}^{2}$.

The junctional architecture of the rectal gland secretory epithelium (few strands, large junctional length densities) is similar to that described for several other hypertonic secretory epithelia [20,34] and is compatible with the recent model for salt secretion in rectal glands [39] and in other $\mathrm{Cl}^{-}$secretory epithelia which posits a conductive paracellular pathway for transepithelial $\mathrm{Na}^{+}$secretion from intercellular space to the lumen to form the $\mathrm{NaCl}$-rich secretory product.
Elasmobranch fish generally inhabit a hypersaline environment and utilize a specialized extrarenal saltsecreting organ, the rectal gland, to maintain ionic homeostasis. This gland lies in the dorsal mesentaries of the peritoneal cavity and secretes a fluid into the intestine with a $\mathrm{NaCl}$ concentration at least twice that of plasma and greater than seawater $[3,5]$. The advent of a method for the isolation and in vitro perfusion of rectal glands [27, 37] paved the way for critical physiological studies which indicate that fluid secretion across the rectal gland epithelium occurs via an active process in which $\mathrm{Cl}^{-}$is transported against both electrical and chemical gradients $[27$, $36,39]$. Stoff et al. [41, 42] also showed that fluid secretion by the rectal gland is stimulated by vasoactive intestinal peptide (VIP) by way of a cyclic AMPdependent pathway. The rectal gland is established, therefore, as a model system for studying the mechanisms underlying $\mathrm{NaCl}$ secretion and joins a growing list of epithelia ( $c f$. ref. [24]) in which active $\mathrm{Cl}^{-}$transport is thought to play a primary role in the formation of the secreted fluid. Based on these investigations, a model was proposed in which the transcellular secretory transport of $\mathrm{Cl}^{-}$generates a favorable electrical potential for the passive paracellular flux of $\mathrm{Na}^{+}$from intercellular space to lumen [39]. Similar models were proposed to account for hypertonic salt secretion in avian salt gland [19, 34], and in teleost branchial [38] and opercular $[17,20]$ epithelia.

A key feature of this model is the proposed presence of a high conductance shunt pathway for $\mathrm{Na}^{+}$ permeation across the occluding junctions between rectal gland secretory cells, similar to the physiologically defined cation-permeable channels described for several absorptive epithelia ( $c f$. ref. [12]). Histological restraints preclude direct electrical measurements of junctional ionic conductivity across rectal gland secretory epithelium. However, Claude and Goodenough [8] and Claude [7] have provided morphological corre- 
lates to low junctional resistivity in "leaky" absorptive epithelia in terms of a demonstrated paucity of strands seen in freeze-fracture images of occluding junctions (zonulae occludentes). In the present study, we have examined rectal gland structure, with particular emphasis on morphology of occluding junctions, in two species of elasmobranch fishes, the spiny dogfish Squalus acanthias and the stingray Dasyatis sabina. Occluding junctions between secretory cells exhibit a morphological simplicity which resembles that described for "leaky" absorptive epithelia and contrasts with the extensive junctional arrays of the stratified rectal gland excretory duct which carries the nascent $\mathrm{NaCl}$-rich secretion to the intestinal canal. In addition, we have applied for the first time morphometric techniques to measure the tortuosity of occluding junctions and have found for the secretory epithelium (and in contrast to the excretory duct) that the linear extent of the shunt pathway available for ionic conductance, expressed in meters of junctional length/ $\mathrm{cm}^{2}$ of luminal surface, is remarkably large.

A preliminary account of this work was presented in abstract form [18].

\section{Materials and Methods}

\section{Animals}

Stingrays Dasyatis sabina were purchased from Gulf Specimen Company, Inc., Panacea, Florida. Spiny dogfish Squalus acanthias were obtained at both the Mount Desert Island Biological Laboratory, Salsbury Cove, Maine and the Marine Biological Laboratories, Wood's Hole, Massachusetts.

\section{Electron Microscopy}

Animals were sacrificed by concussion or by severance of the spinal cord and pithing. Rectal glands from both species, and portions of excretory duct from the dogfish, were removed quickly, cut into small $\left(1 \mathrm{~mm}^{3}\right)$ blocks, and fixed for $120 \mathrm{~min}$ at $22{ }^{\circ} \mathrm{C}$ with $5 \%$ glutaraldehyde in $0.1 \mathrm{M}$ sodium cacodylate buffer $(\mathrm{pH} 7.4$ ) plus $0.25 \mathrm{M}$ sucrose and $0.025 \% \mathrm{CaCl}_{2}$. Following fixation, tissue blocks were rinsed several times in $0.2 \mathrm{M}$ cacodylate buffer $(\mathrm{pH}$ 7.4).

For conventional electron microscopy, tissue blocks were postfixed for $60-90 \mathrm{~min}$ at $22{ }^{\circ} \mathrm{C}$ with $1 \% \mathrm{OsO}_{4}$ in $0.2 \mathrm{M}$ cacodylate buffer containing $0.25 \mathrm{M}$ sucrose. In some instances, $1.5 \%$ potassium ferrocyanide was included in the $\mathrm{OsO}_{4}$ solution to enhance membrane contrast [28]. After rinsing in distilled water, the tissue was dehydrated and embedded in Spurr resin. Thin sections were obtained with diamond knives on a Porter-Blum MT-2B ultramicrotome, picked up on uncoated 200-mesh copper grids, and stained with uranyl acetate and lead citrate.

For freeze-fracture studies, the glutaraldehyde-fixed tissue blocks were infiltrated for at least 60 min with $25 \%$ glycerol in $0.2 \mathrm{M}$ cacodylate buffer ( $\mathrm{pH} 7.4$ ). Small tissue samples then were transferred to gold supports, frozen in Freon 22 cooled in liquid nitrogen, and fractured at $-112^{\circ} \mathrm{C}$ in a Balzers 301 freeze-etch unit equipped with a platinum-carbon gun and a quartz crystal monitor. Replicas of fractured surfaces were cleaned with fullstrength Clorox ${ }^{\circledast}$, rinsed several times in distilled water, picked up on uncoated 200-mesh copper grids, and examined in Philips 201 or 400 electron microscopes.

\section{Morphometric Procedures}

In addition to the specific resistance of the junctional pathway, the amount of paracellular ionic conductance should be directly proportional to the absolute amount of junctional channel available for solute permeation. In order to estimate the linear amount of paracellular pathway per unit area of epithelial surface, we derived a morphometric procedure based on the stereological principles and equations of Weibel and Bolender [45]. Specifically, by relating the line density (i.e., length per unit volume) of occluding junctions $\left(M_{v}\right)$ in thin sections of rectal gland secretory epithelium (and excretory duct) to surface density (i.e., surface area per unit volume) of luminal cell membrane $\left(S_{t}\right)$ in the same sections, we were able to obtain an estimate of junctional tortuosity $\left(M_{v} / S_{v}\right)$. Since to our knowledge this represents the first application of these morphometric procedures to the estimation of this parameter of junctional geometry, the approach is presented in detail below.

Samples from four dogfish and two stingrays were utilized for morphometric analysis. From each fish, tissue blocks were fixed and embedded as detailed in the preceding section. The blocks were randomly oriented during embedding. Four blocks from each dogfish and two from each stingray were sectioned. Sections of silver interference color only were collected on 200-mesh grids. From each block a single grid was selected and on this grid only one section was photographed in order to preclude sampling of the same junctional area in immediately adjacent thin sections. All of the profiles of luminal plasma membrane on that section were photographed at an image magnification of approximately $7,000 \times$. The microscope was calibrated using a standard replica grating with a line frequency of 2,160 lines/mm (Ladd Research Industries, Inc. Burlington, VT). The number of micrographs obtained from a single section varied from four to sixteen. Negatives were photographically enlarged to a final print magnification of $18-20,000 \times$ and the prints were overlaid with a transparent sheet containing a coherent square test lattice where the distance $(D)$ between test points $(P)^{1}$ was $20 \mathrm{~mm}$. In our preliminary analyses, several micrographs were also measured using lattices with $D$ equal to 5 and $10 \mathrm{~mm}$. The mean values for junctional parameters obtained using each of these three lattices differed by less than $3 \%$ $(P>0.5)$. The $20-\mathrm{mm}$ test lattice was chosen for routine use since data could be more rapidly collected using this dimensional test grid. A total of 20 to 30 micrographs were analyzed for each fish.

In practice, three parameters were determined from each micrograph. The total number of test points $\left(P_{T}\right)$ representing grid squares in the test lattice that contained profiles of luminal plasma membrane which intersect either of the two test lines $(D)$ extending from each test point was determined. The total number of (apical termini of) occluding junctional profiles $\left(Q_{j}\right)$, all of which lie within these squares, then were counted, as were intersections of luminal plasma membrane profiles $\left(I_{p m}\right)$ with the test lines. The numerical values for each of these three parameters were inserted in the following equations to obtain the length of occluding junction per unit area of epithelial surface. The length density of occluding

1 Test points $(P)$ on the coherent square lattice grid overlay were defined in this analysis as the intersections of grid lines at the upper left-hand corners of the grid squares. Test lines $(D)$ of $20 \mathrm{~mm}$ length extended horizontally to the right and vertically downward from each test point. Thus, two test lines were associated with each test point. See reference [45] for further discussion of these parameters and their derivation. 


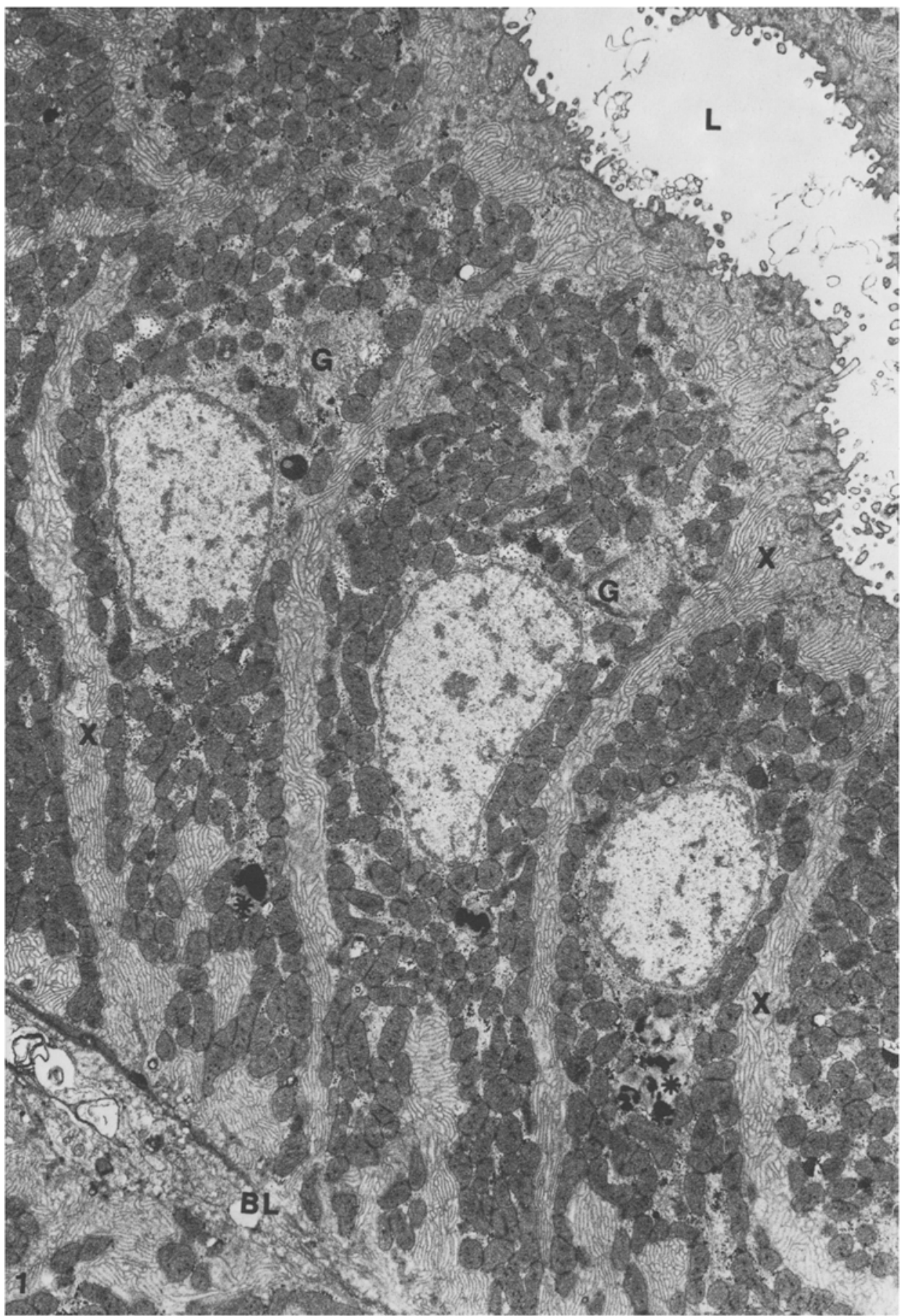

Fig. 1. Secretory tubules in the elasmobranch rectal gland are composed of a simple columnar epithelium. In this low-magnification electron micrograph, portions of several secretory cells from the rectal gland of the dogfish are shown extending from the basal lamina $(B L)$ to the tubular lumen $(L)$. Nuclei are centrally located and are surrounded by clusters of mitochondria. The basolateral margins of the cells are characterized by closely packed plications of the cell surface $(X)$ which define tortuous intercellular spaces. The cytoplasm is moderately dense and contains profiles of lysosomes $(*)$, Golgi membranes $(G)$ and glycogen. Dogfish rectal gland. $4,800 \times$

junctions $\left(M_{v}\right)$ contained within the selected test area $\left(A_{T}\right)$ was determined by the formula: $\left(M_{v}\right)=2 Q_{\mathrm{J}} / A_{T}$ where $A_{T}=P_{T} \cdot d^{2}$, and $d=D /$ magnification. Surface density $\left(S_{v}\right)$ of luminal plasma membrane within the selected test area was determined by the formula:
$S_{v}=2 \cdot I_{p m} / L_{T}$, where $L_{T}$, the total length of the test line, equals $P_{T} \cdot 2 d$. For derivations of these formulas, see Weibel and Bolender [45]. The linear length of occluding junction per unit of luminal surface area $(1 p)$ was then obtained by the ratio $M_{v} / S_{v}$ and ex- 


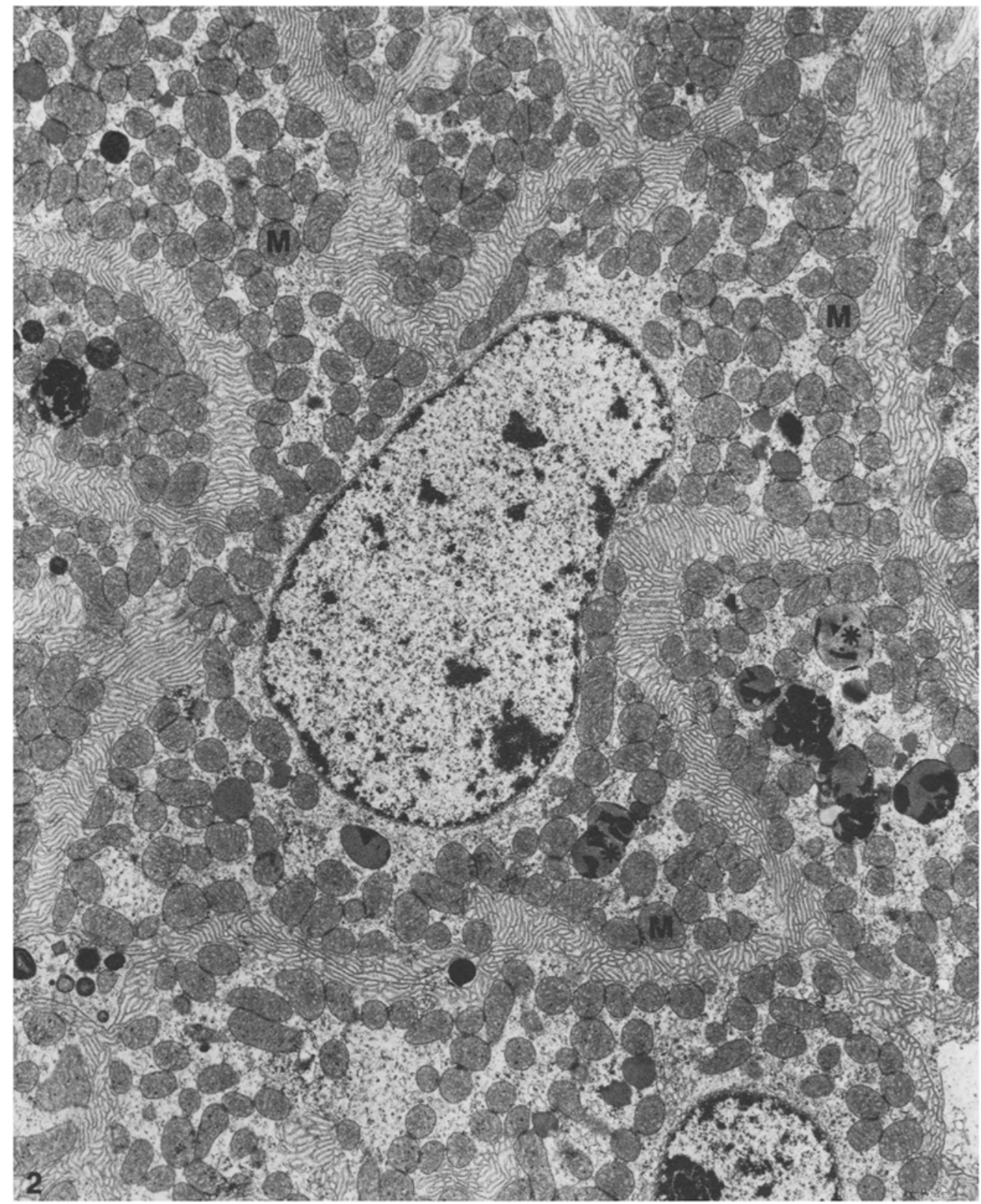

Fig. 2. The intercellular channels that form the boundaries between adjacent secretory cells are illustrated in this transverse section through the nuclear level of the epithelium. Most of the cytoplasmic volume is occupied by mitochondria $(M)$, although clusters of lysosomes (*) are also prominent inclusions. Note that the body of the cell that occupies the center of the field is extended into long arms that interdigitate with extensions from neighboring cells. Dogfish rectal gland. $11,700 \times$

pressed as $\mathrm{m} / \mathrm{cm}^{2}$. This relationship has also been arrived at independently by Mayhew [31] in a recent review of stereological relationships.

For quantitative analysis of junctional depth and strand number, replicas of freeze-fractured tissue blocks were analyzed by the procedure of Claude and Goodenough [8].

\section{Results}

Histological and ultrastructural characteristics of rectal glands of elasmobranch fish were described pre- viously $[1,15]$ and are reviewed here briefly for purposes of orientation, particularly as they relate to freeze-fracture data. The rectal gland in both the dogfish and the stingray is a cylindrical-shaped organ which is supported by the dorsal mesentary. The parenchyma consists of simple and branched secretory tubules which radiate from a central canal and abut blindly on an outer fibromuscular capsule. The central canal is continuous with an excretory duct which 


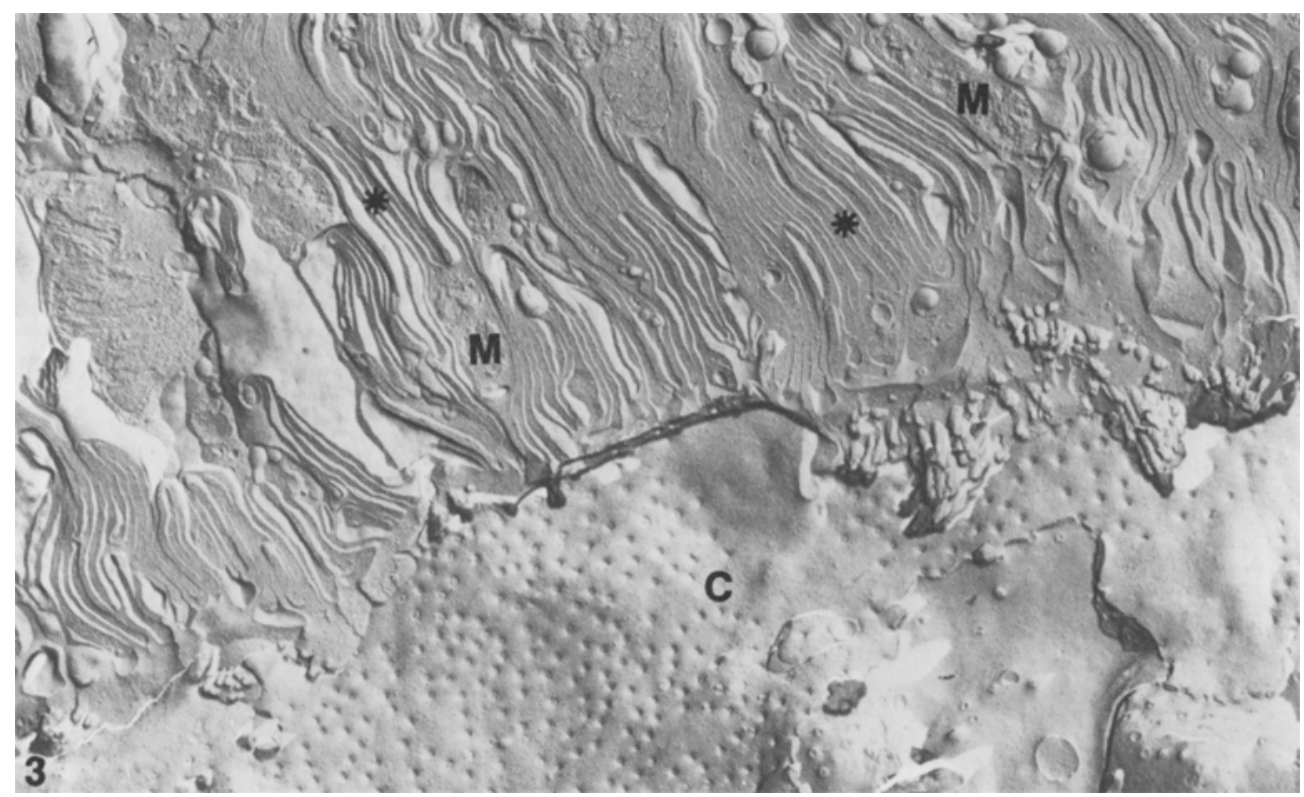

Fig. 3. The basal surfaces of secretory cells in the rectal gland lie in close juxtaposition to fenestrated capillaries ( $C$ ). Folding of the basolateral plasmalemma is extensive (*). Mitochondria $(M)$, most of which are cross-fractured in this replica, are intimately associated with these folds. Dogfish rectal gland. $13,300 \times$

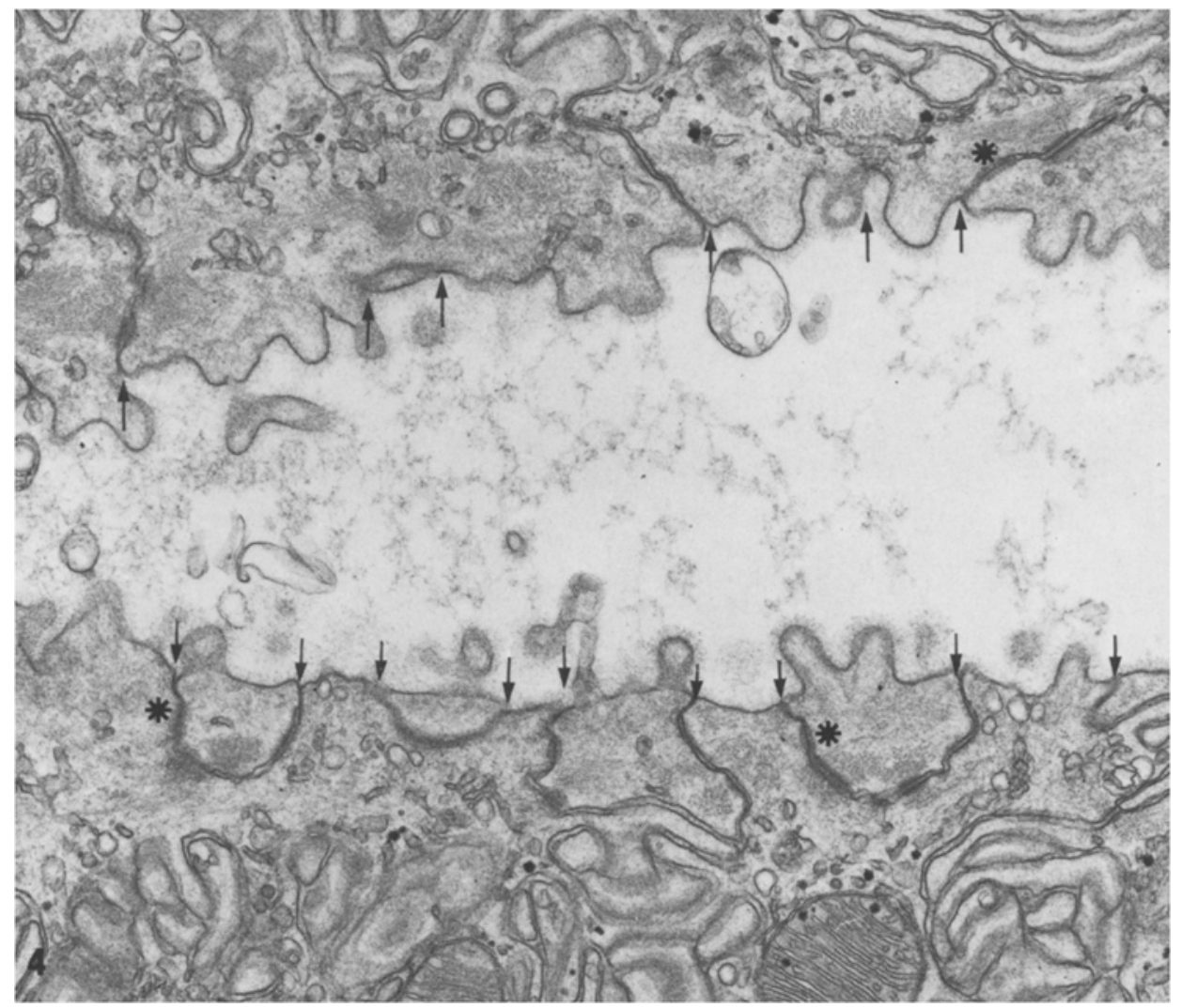

Fig. 4. The luminal surfaces of the secretory tubules are covered by a glycoprotein-rich surface coat and bear numerous microvilli. Apical portions of neighboring secretory cells interdigitate with one another, thereby greatly increasing the density of occluding junctional profiles (arrows) seen subjacent to the interlocking apical interface (compare with Fig. 5). A cortical zone beneath the free surface is present and is characterized by a dense feltwork of microfilaments, some of which are associated with well-developed zonulae adherentes (*). $20,300 x$ 


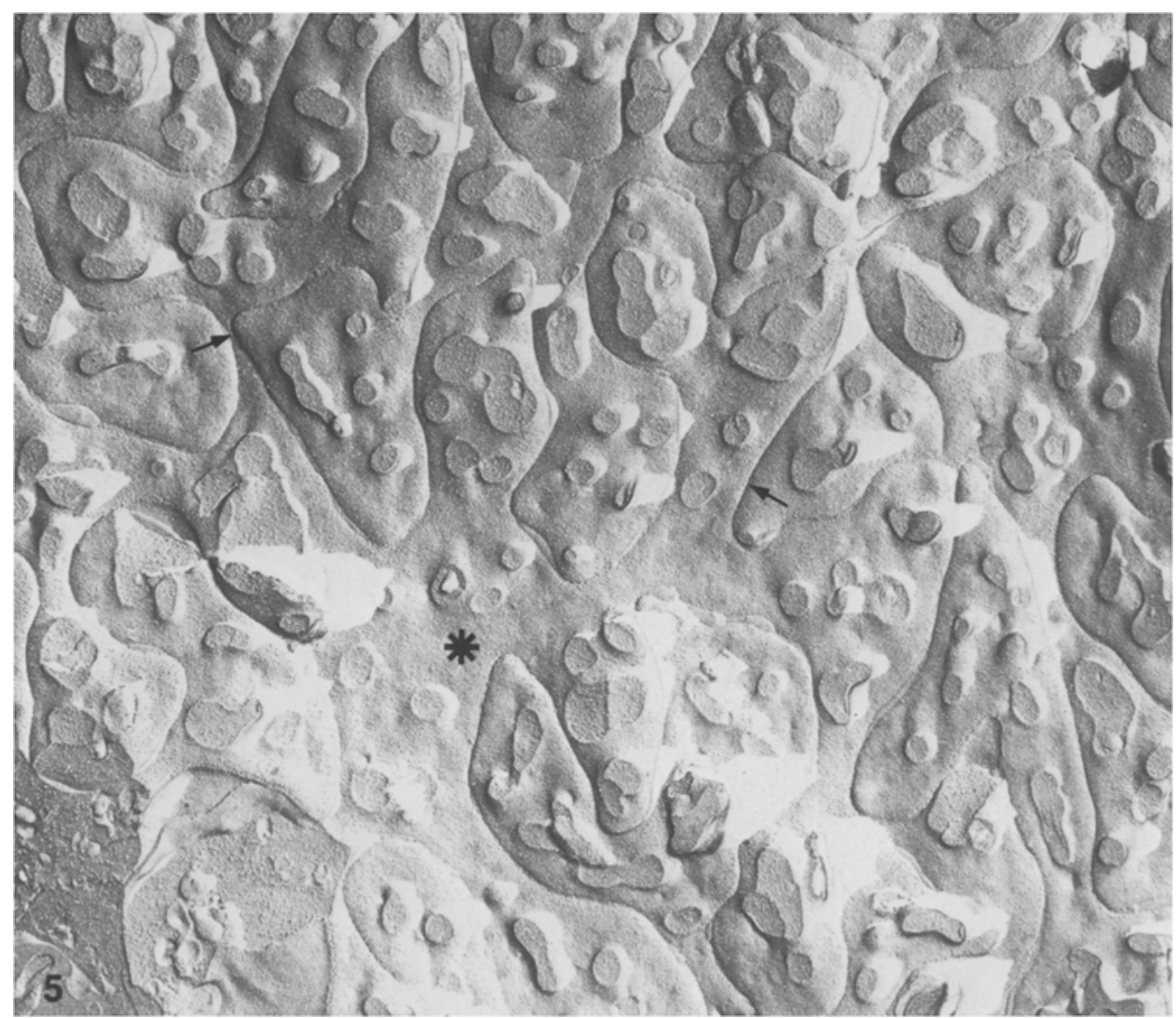

Fig. 5. This freeze-fracture view of the luminal membrane (with cross-fractured microvilli) in the dogfish secretory epithelium illustrates that apical cell surfaces are narrow and intermesh with one another like interlocking fingers. The occluding junctions lie deep to the apical furrows (arrows). Much of the free surface shown here belongs to a single cell, since one can trace the tortuous luminal interface (starting at the asterisk) for considerable distances in all directions without crossing a furrow to an adjacent epithelial cell surface. Cross-fractured cytoplasm is revealed at the lower left corner of the micrograph. 13,300x

Table 1. Geometrical parameters of occluding junctions in the secretory epithelium of the elasmobranch rectal gland

\begin{tabular}{llll}
\hline Species & Strand number & $\begin{array}{l}\text { Depth } \\
(\mathrm{nm})\end{array}$ & $\begin{array}{l}\text { Length density } \\
(l p)\left(\mathrm{m} / \mathrm{cm}^{2}\right)\end{array}$ \\
\hline Squalus acanthias & $3.56 \pm 0.24(16)$ & $56 \pm 5(16)$ & $66.8 \pm 2.5(142)$ \\
Dasyatis sabina & $1.96 \pm 0.15(27)$ & $18 \pm 3(27)$ & $74.9 \pm 4.6(42)$ \\
\hline
\end{tabular}

Strand number and junctional depth were determined from replicas of freeze-fractured rectal glands according to the method of Claude and Goodenough [8]. Length densities, which represent the linear extent of occluding junction in a unit area of luminal epithelial surface, were calculated from stereological measurements on thin sections (see Materials and Methods). Sampling for morphometric analysis was carried out using procedures described by Weibel and Bolender [45]. Values listed represent the means \pm SEM of $(n)$ electron micrographs analyzed.

penetrates the intestinal wall and opens just posterior to the spiral valve.

Secretory tubules in dogfish and stingray are composed of a simple columnar epithelium (Fig. 1). As in other hypertonic secretory epithelia (cf. ref [20]), the secretory cells are characterized by extensive amplification of basolateral cell surfaces and by a close association of these densely packed plasmalemmal folds with a large population of mitochondria (Figs. 1-3). $\mathrm{Na}^{+}, \mathrm{K}^{+}$-ATPase is exclusively associated with these folded membranes $[21,26]$. The plications of the basolateral membrane interdigitate with those of neighboring cells. In addition, the bodies of the secretory cells themselves extend laterally as mitochondria-rich cytoplasmic arms which intermesh with similar extensions from neighboring cells (Fig. 2). When viewed in cross-section (Fig. 2), the epithelium exhibits a cytoarchitecture in which a series of tortuous intercellular channels appear to penetrate an almost coherent mitochondrial matrix.

The intercellular channels open basally onto a continuous basal lamina (Figs. 1 and 3 ) and a subjacent peritubular connective tissue invested richly with fenestrated capillaries (Fig. 3). Apically, the intercellular space is separated from the luminal compartment by occluding junctions (Figs. 1 and 4). The apical plasma membrane exhibits a glycoprotein-rich sur- 


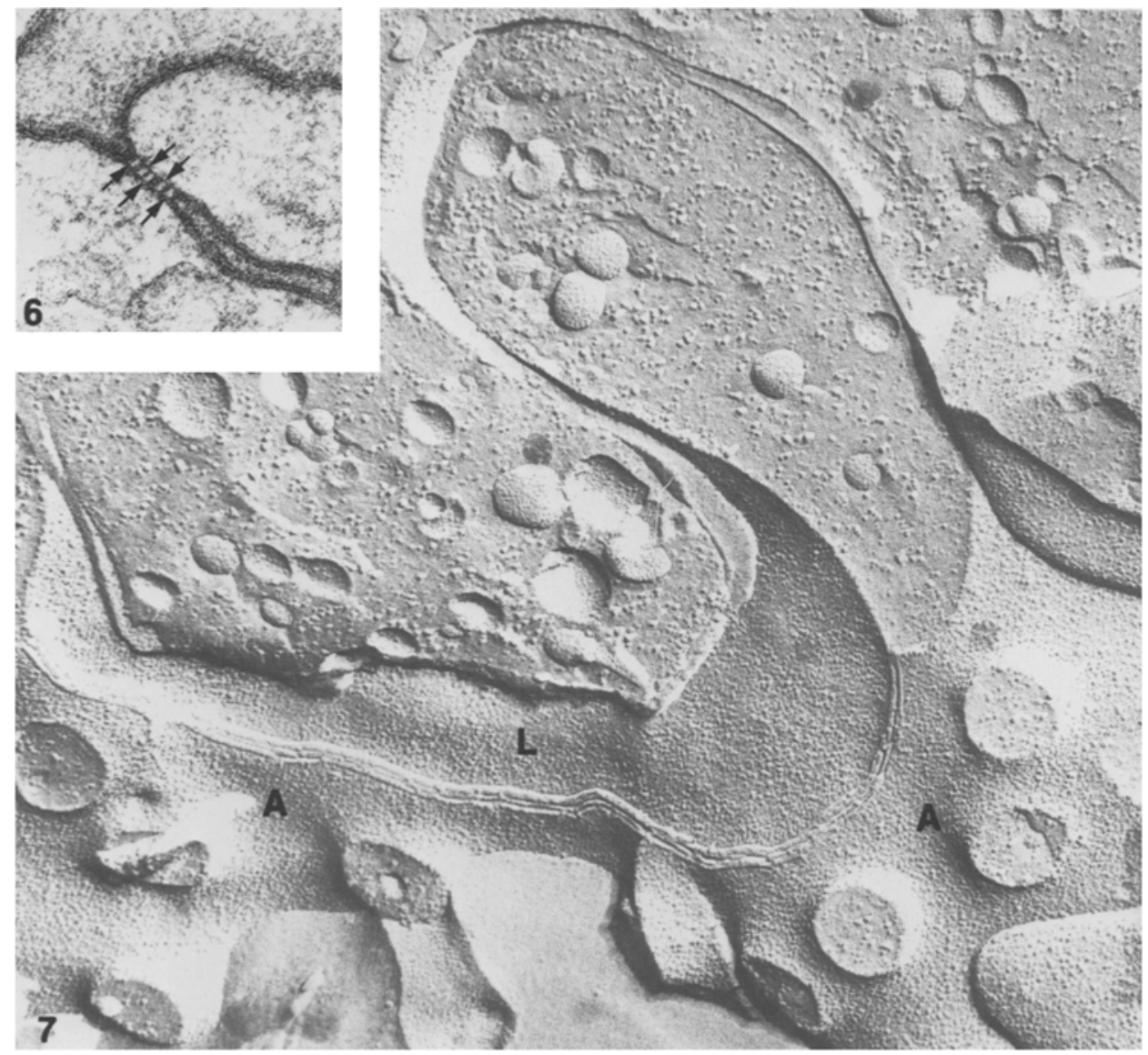

Fig. 6. When tissues are exposed to potassium ferrocyanide during post-fixation, occluding junctions appear in negative image as a series of dots or short bars (arrows) which extend from cytoplasmic leaflet to cytoplasmic leaflet of opposing epithelial cell surfaces. They are separated from one another by electron-dense ferrocyanide which penetrates the junction and stains the plasmalemmal leaflet bordering the intervening intercellular spaces. Some stain is trapped within these spaces as well. These junctional elements, which measure 10-15 nm in width and 4-10 nm in length, represent cross-sectioned views of junctional strands seen in freeze-fractured replicas. In this micrograph from the dogfish rectal gland, the junction consists of five junctional elements. Note that the intercellular space at the apical and basal poles of the junction appears nearly obliterated by the close approximation of the outer leaflets of the plasmalemma (also see Fig. 9). 105,000 $\times$

Fig. 7. This freeze-fracture replica from dogfish rectal gland shows an occluding junction which consists of two to three closely apposed ridges separating the $P$ fracture faces of apical $(A)$ and lateral $(L)$ plasma membranes. Mean junctional depth was $56 \pm 5 \mathrm{~nm}$. $51,000 \times$

face coat and numerous blunt microvilli and is supported by a cortical zone containing cytoplasmic microfilaments often associated with the junctional plaques of well-developed zonulae adherentes (Fig. 4).

\section{Occluding Junctions in Rectal Gland Secretory Epithelium}

When viewed in thin sections, the apical portions of the secretory cells appear narrow and highly irregular in shape (Figs. 1 and 4). The intermeshing of neighboring cells near the apex defines, therefore, occluding junctions of marked tortuosity. This is expressed in thin sections by a high density of crosssectional profiles per unit of luminal surface area (Fig. 4) and, in freeze-fracture images of the apical surface, as a corresponding enhancement of the linear extent of the junction (Fig. 5). Morphometric measurements of the length density of occluding junctions in the secretory epithelium of the dogfish and of the stingray (see Materials and Methods) gave values of $66.8 \pm 2.5$ and $74.9 \pm 4.6$ meters of junctional length per $\mathrm{cm}^{2}$ of luminal surface area, respectively (Table 1).

In contrast to the large length densities, occluding junctions in both species are shallow in their apical to basal extent (Fig. 4). In tissue post-fixed with $\mathrm{OsO}_{4}$-potassium ferrocyanide solutions, the shallow region of junctional contact is resolved as a series of subunits or short bars (Figs. 6 and 9). These elements extend from cytoplasmic leaflet to cytoplasmic leaflet of the opposing epithelial surfaces (Fig. 6) and 


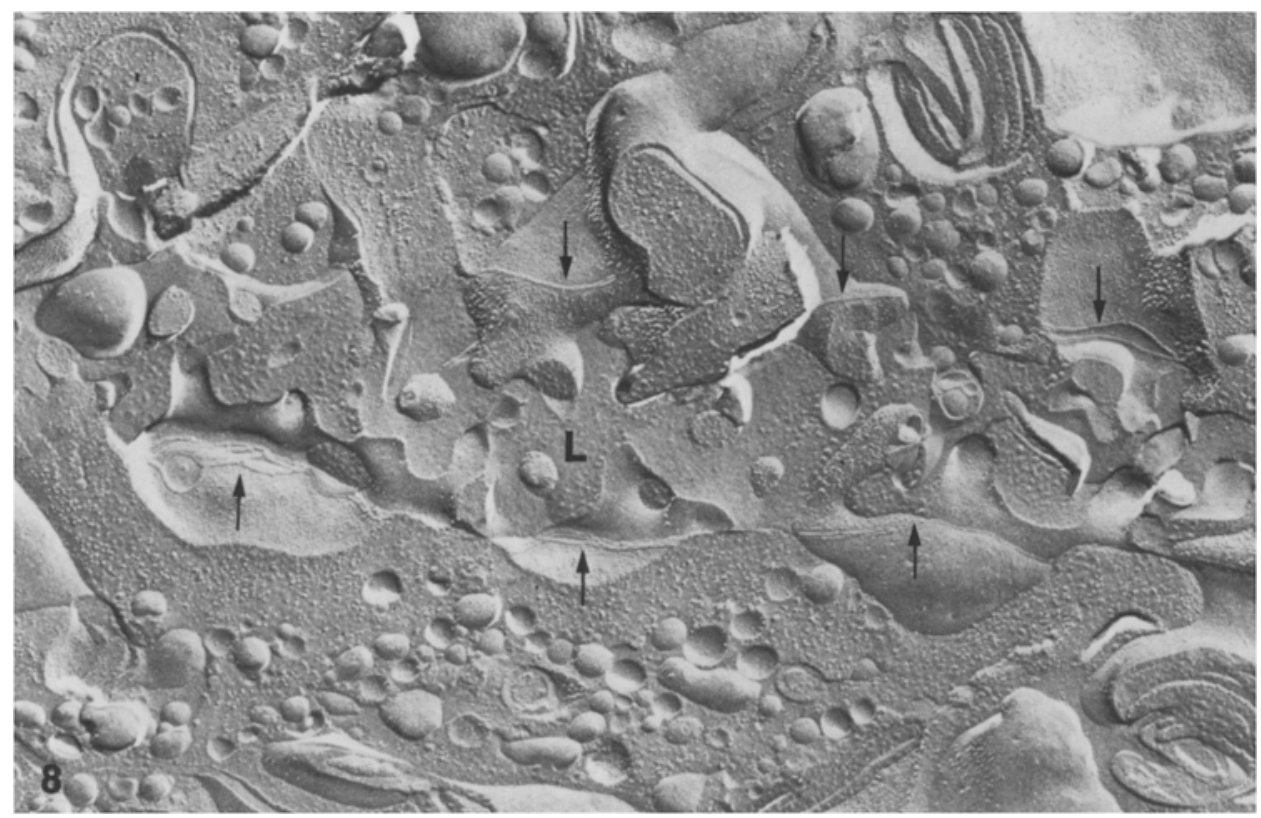

Fig. 8. The range in the number of junctional strands in the dogfish rectal gland epithelium is illustrated in this freeze-fracture image. Portions of cross-fractured lumen $(L)$ extend across the central part of the replica. The number of juxtaposed and parallel junctional strands and grooves separating apical from lateral fractured surfaces on either side of the lumen (arrows) varies from two to five. $22,750 \times$

appear to represent cross-sectional profiles of the closely juxtaposed junctional strands seen in comparable freeze-fracture images (Fig. 7). In the dogfish, the number of junctional elements seen in thin section, such as those in Fig. 6, ranged from 2-5 and this encompassed the range of strands generally resolved by freeze fracture (Fig. 8). Variability in strand number was seen even within the same luminal profile. Average strand number in the dogfish, determined by the techniques suggested by Claude and Goodenough [8], was $3.5 \pm 0.2$ with an average total depth of $56 \pm 5 \mathrm{~nm}$ (Table 1). In contrast, strand number in the stingray was less variable, ranging from 1 to 3 closely opposed elements (Figs. 9 and 10) with an average strand number of $2.0 \pm 0.2$ and a mean depth of $18 \pm 3 \mathrm{~nm}$ (Table 1 ).

\section{Structural Features of the Collecting (Excretory) Duct}

The central collecting duct, and the extraglandular excretory duct with which it is continuous, is lined by a stratified epithelium of 4 to 8 cell layers. In agreement with the initial study of Bulger [2], our observations indicate that the epithelium bears many ultrastructural features which closely resemble those described by Choi [6] for the amphibian urinary bladder. In particular, the majority of superficial cells bordering the lumen exhibit moderately plicated basolateral surfaces, microvillar ridges along the luminal interface, and characteristic electron-dense granules in the subapical cytoplasm (Fig. 11). These granular cells, together with the occasional mitochondria-rich cells and mucous cells described by Bulger [2] are analogous to the complementary cell types of the urinary bladder [6].

In contrast to the secretory epithelium, junctions between superficial cells in the duct are remarkably extensive and consist of anastomosing strands rather than closely opposed parallel arrays (Fig. 12). From a limited sample of freeze-fracture images of the collecting duct in the dogfish, a mean of 12 interlocking strands (range 10-18), comprising a junctional depth of $0.6-0.8 \mu \mathrm{m}$, was observed. Junctional architecture was identical in the extraglandular excretory duct. Examination of thin sections such as that shown in Fig. 11 indicate that the superficial cells exhibit large apical faces with a consequent reduction in the frequency of cross-sectioned junctional profile per unit area of surface membrane. This observation was confirmed by morphometric analysis of 26 micrographs from thin sections of three tissue blocks, each from a different dogfish gland. The mean length of junction per unit of luminal surface area was $7.6 \pm 0.1 \mathrm{~m} / \mathrm{cm}^{2}$.

\section{Discussion}

Electrophysiological and electron-microscopic studies have established the occluding junction (zonula occlu- 

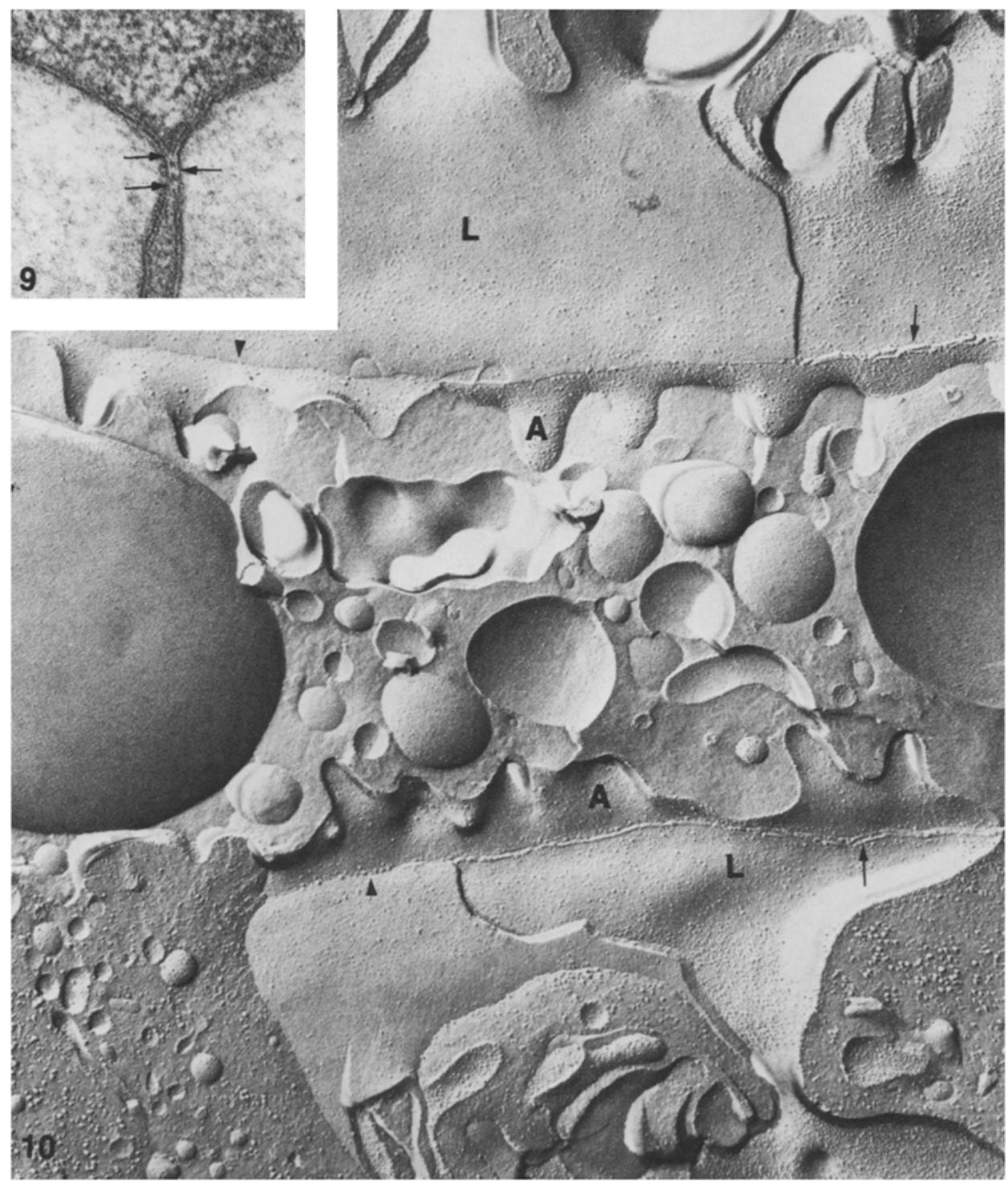

Fig. 9. The morphological characteristics of the stingray rectal gland are similar to those of the dogfish except that the occluding junctions are not as extensive. In this electron micrograph of ferrocyanide-stained stingray rectal gland epithelium, the zonula occludens appears to consist of three junctional elements (arrows). 146,250x

Fig. 10. This freeze-fracture replica from stingray rectal gland epithelium shows one to two junctional strands (arrows) or grooves (arrowheads) between apical $(A)$ and lateral $(L)$ plasmalemmal fracture faces. A portion of the tubular lumen is shown in cross-fracture. In the stingray, junctional strands are observed often to consist of short bars, sometimes with discontinuities, and isolated particles are often present in junctional grooves. Average junctional depth was $18 \pm 3 \mathrm{~nm}$. $36,000 \times$

dens) as the high-conductance paracellular pathway for ionic diffusion in absorptive epithelia which exhibit low transepithelial resistance $[12,25,29,47]$. A morphological correlation to observed differences in transmural resistance among absorptive epithelia was provided by the comparative studies of Claude and Goodenough [8]. In their studies low resistance epithelia were shown to exhibit few junctional strands in freeze-fracture images, whereas high-resistance epithelia were characterized by large numbers of anasto- mosing strands. Correlation between junctional morphology and resistance has been confirmed by others (e.g., [33]; see also references in Claude [7]). Based on such data, Claude [7] derived a mathematical formulation which suggests that junctional resistance is related exponentially to the number of strands in the zonula occludens.

Considering the above, it would seem that tissues which generate and maintain steep transepithelial solute gradients would exhibit high transmural resistance 


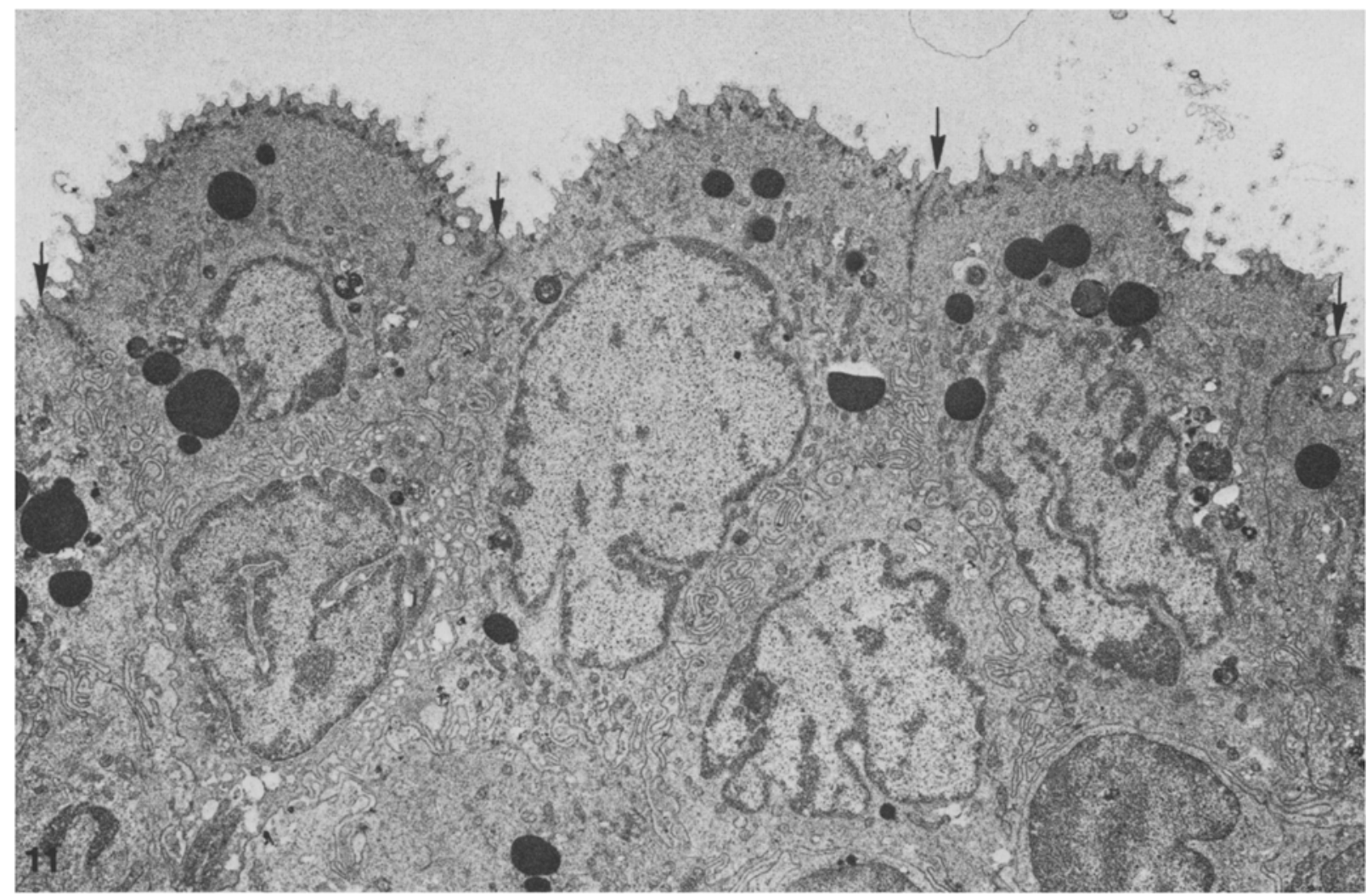

Fig. 11. The central collecting duct of the rectal gland drains the secretory tubules and carries the $\mathrm{NaCl}$-rich secretion to the intestine. The epithelium is stratified, with four to eight cell layers interposed between the basal and luminal epithelial surfaces. The majority of cells in the luminal stratum of the collecting duct resemble the granular cells of the amphibian urinary bladder (cf. [6]). Apical surfaces display short projections which in tangential sections are seen as anastomosing microridges. Numerous granules occupy the cytoplasm immediately subjacent to the apical plasmalemma. Basolateral cell surfaces display a moderate degree of elaboration. Junctions between adjacent cells at the luminal epithelial surface (arrows) are of much greater depth than those seen in the secretory epithelium proper. Dogfish rectal gland. $4,100 \times$

values [25] and extensive junctional arrays which, simplistically, might provide a structural barrier to dissipation of the gradient. This appears to be the case for many hypertonic absorptive epithelia [7, 8], although exceptions to this correlation have been reported, particularly for epithelia like ileum and renal distal tubules which are leaky to lanthanum solutions despite moderate resistance values and relatively welldeveloped junctions $[30,43]$. We are unaware of any examples of epithelia which show high-electrical resistance and poorly developed junctions. In the salt secretory rectal glands of dogfish [5] and stingrays [4], rectal gland fluid to plasma $\mathrm{NaCl}$ ratios of 2-2.5 are maintained, although the glandular secretion is isosmotic with plasma [5], the balance in plasma tonicity being maintained by urea and trimethylamine oxide retention $[23,40]$. Despite the $\mathrm{NaCl}$ gradient, the number of junctional strands seen in the secretory epithelium of both species studied is low, with a mean of $2.0 \pm 0.2$ in the stingray and $3.5 \pm 0.2$ in the dogfish (Table 1). On strictly morphological grounds these occluding junctions are comparable to those seen in epithelia such as proximal tubules which are classified electrically as very leaky and generally exhibit one, or possibly two junctional strands $[7,8,33]$. Other studies have shown that junctions in rectal glands from sharks and rays are penetrated by lanthanum [44]. Although transglandular potentials have been measured for dogfish rectal glands and are moderately low $(15 \mathrm{mV}$ lumen negative in glands stimulated with theophylline and dibutyryl cyclic AMP [39]), measurement of transmural potential and resistance values across the secretory epithelium itself have not been made due to methodological problems inherent in the histological organization of the gland. Accordingly, the implied relationship between the observed simplicity of junctional structure and the presence of a high conductance junctional pathway is compelling but remains circumstantial. Although no information exists as to whether the collecting duct serves only as a conduit for the nascent secretion or plays some role in modification of the secretory product, the elaborate structure of the junctions between superficial intra- and extraglandular duct cells (Fig. 12). which 


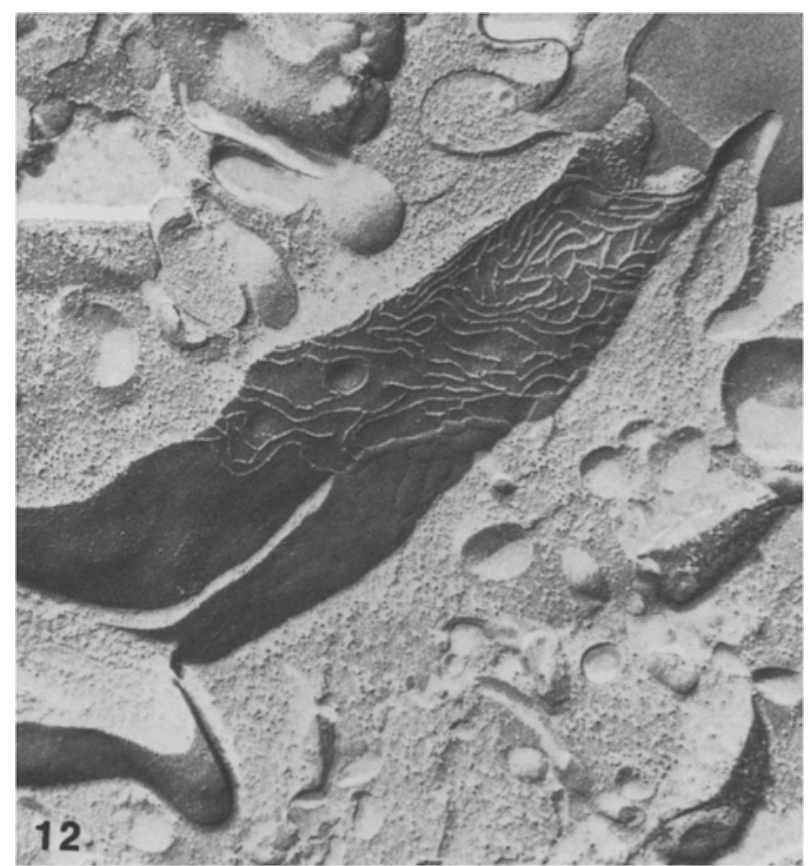

Fig. 12. In freeze-fracture replicas of collecting duct, as seen in this micrograph from the dogfish rectal gland, occluding junctions typically consist of an extensive network of anastomosing strands or grooves. These networks may extend up to $1 \mu \mathrm{m}$ in depth along the lateral cell borders. $37,000 \times$

is in striking contrast to that of the secretory epithelium (Figs. 7 and 8), suggests that the ductal paracellular pathway, at least, may be relatively impermeable to the NaCl-rich luminal content. The similarity in structure between the duct cells (Fig. 11) and epithelial cells of the amphibian urinary bladder [6], however, suggests that the ductal epithelium might have an ancillary function in salt transport, a factor which should be considered when attempting to relate transglandular potentials directly to electrical events occurring at the level of the secretory epithelium.

Aside from the complexity of the paracellular barrier in terms of the number of strands, and the chemical composition of the barrier itself, the absolute amount of junction available for ionic permeation per unit of luminal surface area $(l p)$ plays an important role in determining the extent of paracellular conductance. Values for $l p$ for most transporting epithelia have not been determined, although Claude [7] estimated numbers ranging from $6-20 \mathrm{~m} / \mathrm{cm}^{2}$ for a variety of epithelia based on the assumption that the cells are square. DiBona and Mills [14] analyzed the geometrical relationship between cell size and the amount of edge for epithelia whose cells approximate a hexagonal array and showed that $1 p$ for tight bullfrog urinary bladder was $6.5 \mathrm{~m} / \mathrm{cm}^{2}$, whereas the smaller cells of leaky frog gallbladder had an $1 p$ of $26 \mathrm{~m} / \mathrm{cm}^{2}$. In rectal glands of both the dogfish and stingray, the secretory cells are narrow (Fig. 4). Moreover, the topology of the mucosal surface reveals a striking tortuosity of cell borders between the narrow interdigitations of the apical interface (Figs. 4 and $5)$. These geometric factors serve to greatly enhance $l p$, and this is reflected in the morphometric analysis of this parameter where values of $66.8 \pm 2.5 \mathrm{~m} / \mathrm{cm}^{2}$ and $74.9 \pm 4.6 \mathrm{~m} / \mathrm{cm}^{2}$ were derived for the dogfish and stingray, respectively (Table 1 ). These figures compare well with the corresponding value for the structurally analogous very leaky proximal tubule which, as estimated from stereological data in Welling and Welling [46], is approximately 50-100 meters of junction $/ \mathrm{cm}^{2}$ of luminal surface. The rectal gland values are particularly impressive when one considers that the contribution of the microvillar border to total luminal membrane area was not included in the calculation for the proximal tubule. Calculated on this basis (i.e., a flat luminal surface), $1 p$ for the rectal glands is twofold higher. Just as there is a marked contrast in the number of junctional strands seen in the secretory and ductal epithelium, $l p$ for the collecting duct is small $\left(7.6 \pm 0.1 \mathrm{~m} / \mathrm{cm}^{2}\right)$, corresponding to the $1 p$ of the large hexagonally packed cells of the amphibian urinary bladder [14] with which it shares these and other $[2,6]$ morphological characteristics (see Fig. 11).

Taken together, the extensive amount of junction available for ionic permeation and the paucity of intervening resistive elements (e.g., junctional strands) in the extracellular pathway itself are consistent with the possibility that a significant proportion of ionic conductance across rectal gland secretory epithelium is paracellular. Such a pathway is implicit in the recent model for rectal gland salt secretion developed by Silva et al. [39] and described in Fig. 13. Similar models have been proposed for teleost gill [38] and opercular epithelia $[17,20]$, and for avian salt glands $[19,34]$. Supporting physiological data for the rectal gland has been presented and discussed in detail in several recent publications [22, 39, 41, 42].

The present study, while providing a compatible morphological basis for the proposed ionic conductance across rectal gland occluding junctions, does not provide information on other characteristics of the junction that are critical to this model (Fig. 13). In particular, the junctions must be differentially permeable to $\mathrm{Na}^{+}$over $\mathrm{Cl}^{-}$and relatively impermeable to other solutes, notably urea and trimethylamine oxide.

Recent electrical and ion flux studies [9, 10], have shown that $\mathrm{Na}^{+}$movement across another salt-secreting epithelium, the teleost operculum, is passive. Since bidirectional fluxes of $\mathrm{Na}^{+}$could be blocked by triaminopyrimidine (TAP) [11], a compound which blocks the cation-selective shunt pathway [12, 32], 


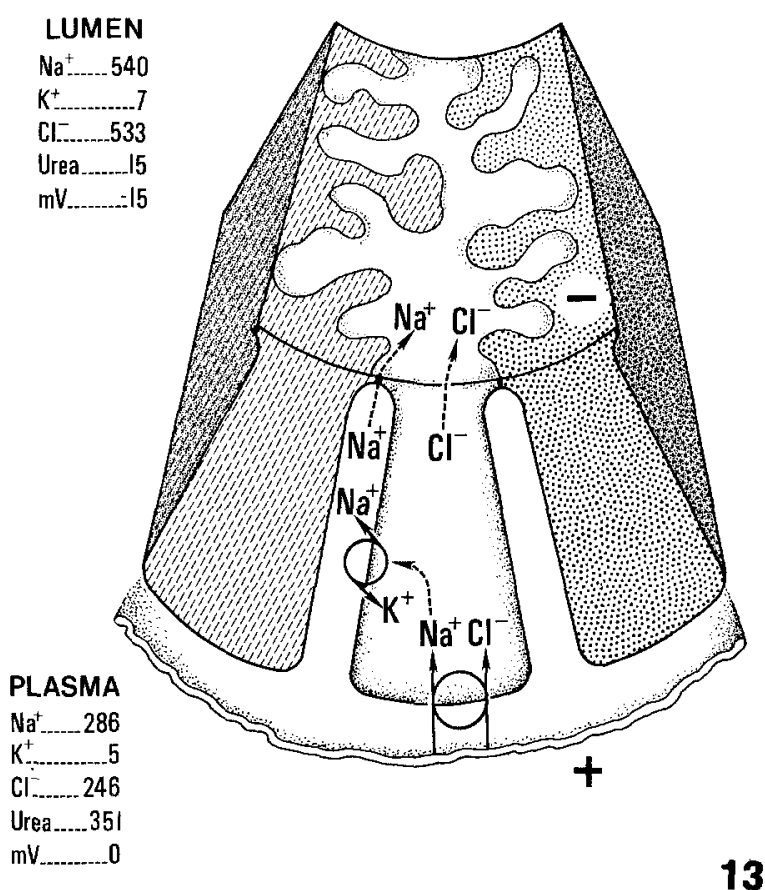

Fig. 13. This diagram shows the hypothetical model for salt secretion in the rectal gland epithelium proposed by Silva et al. [39] and modified here to incorporate the morphological data of the present study. The key features of this model are: 1) the presence of basolateral $\mathrm{Na}^{+}, \mathrm{K}^{+}$-ATPase which maintains a favorable intracellular $\mathrm{Na}^{+}$gradient to drive the coupled uptake of $\mathrm{Cl}^{-}$into the cell against a steep electrochemical potential; 2) the movement of $\mathrm{Cl}^{-}$down a favorable electrical gradient from cell interior to lumen (electrochemical potential favoring $\mathrm{Cl}^{-}$efflux $=8.3 \mathrm{mV}$ (ref. [38]); and, 3) the passive diffusion of $\mathrm{Na}^{+}$across intercellular junctions into the luminal compartment due to the favorable potential created by the transcellular movement of $\mathrm{Cl}^{-}$. Junctions between adjacent secretory cells are shallow and consist generally of two or three closely juxtaposed parallel strands. The linear amount of the paracellular pathway is extensive due to the marked tortuosity of the apical portions of the secretory cells. These two features may constitute a morphological basis for the proposed high junctional conductance for $\mathrm{Na}^{+}$. Solute composition of dogfish plasma and secretory fluid, expressed in millimoles/liter, is taken from Burger and Hess [5]. The potential difference is transglandular and was determined for isolated perfused rectal glands after stimulation with cAMP and theophylline [9]

the aggregate data lend support to the proposed presence of a high-conductance extracellular pathway for $\mathrm{Na}^{+}$in hypertonic secretory epithelia. Degnan and Zadunaisky [11] also reported that unlike $\mathrm{Na}^{+}$flux, urea flux (and passive $\mathrm{Cl}^{-}$influx) was unaffected by $\mathrm{TAP}$, suggesting that at least in the opercular epithelium, the paracellular leak pathway for $\mathrm{Na}^{+}$may differ from the transepithelial pathway for urea. Minimally, the data suggest that junctional permeability to cations need not necessarily entail substantial permeability to small hydrophilic nonelectrolytes like urea which in elasmobranchs comprise substantial portions of the osmotically active solutes in plasma and intracellular fluids [23], but are absent in significant amounts from NaCl-rich rectal gland secretions [5]. Although not a consideration for the isotonic rectal gland secretion, the generalization of the model presented in Fig. 13 to other secretory epithelia must include consideration of the additional problem of the need for a high junctional $\mathrm{Na}^{+}$conductance concomitant with a low paracellular water permeability, since in epithelia like the avian salt gland and the seawater-adapted teleost gill and operculum, the secretion is hypertonic to plasma. Differential water permeabilities of the transcellular and paracellular routes are not well-characterized, however, for most epithelia $[12,13]$, and data are available which either support or rule out a predominant junctional route for water flux across leaky epithelia ( $c f$. Discussion and references in [37]). If paracellular water movement proves to be substantial, the model would be seriously compromised, although dilution of a hypertonic secretion conceivably might be limited to some extent if the tonicity within the tortuous intercellular spaces, maintained by basolateral $\mathrm{Na}^{+}, \mathrm{K}^{+}$-ATPase, is high. In this regard, Ellis et al. [16] suggested that such a mechanism itself might be employed to concentrate a primary isotonic secretion.

In previous work from this laboratory, we showed that junctions in the secretory epithelium of the avian salt gland [34] and between salt secretory chloride cells in seawater-adapted teleost opercular skin [17, 20], also consist generally of two strands, although single and occasional multiple strands were seen. ${ }^{2}$ Although not measured quantitatively in these studies, examination of thin-section and freeze-fracture images of these epithelia demonstrate that, as in the present study, the apices of these secretory cells are narrow and intertwine to produce a large ratio of junctional length to luminal surface area. Moreover, in spite of the disparate phylogenetic background of these animals, junctions in all of these salt secretory epithelia share an additional structural feature in that the strands are generally parallel to one another and in close contact along their entire extent. These observations indicate that this junctional architecture (few strands which are closely juxtaposed, large $1 p$ ) may be a fundamental structural and, presumably func-

\footnotetext{
$2 \quad$ Sardet et al. [35] and Ellis et al. [16] reported that single strands were predominant between secretory cells in teleost gill and salt gland, respectively. However, as demonstrated in the salt gland [34] closely juxtaposed doublets may be interpreted as single strands due to shadowing angle or, more frequently, to fractures which pass between strands ( $P$ - to $E$-face transitions between adjacent cells) to generate a strand with a closely applied and hard to resolve groove.
} 
tional characteristic of epithelia which secretery hypertonic $\mathrm{NaCl}$ solutions. The closely juxtaposed arrangement of strands is in marked contrast to the anastomosing network characteristically seen in absorptive and in nontransporting epithelia. In heterogenous secretory epithelia such as the operculum, junctional strands between secretory (chloride) cells are parallel and closely apposed, while those between presumably nontransporting superficial (pavement) cells are in the form of an elaborate honeycomb [17, 20]. A similar transition in junctional structure was noted between mitotically active peripheral cells and principal secretory cells in avian salt gland [34], and in the present study between rectal gland secretory and ductal epithelium (Figs. 7 and 12). Closely juxtaposed parallel strands are not, however, entirely unique to secretory epithelia. A similar junctional arrangement has been described in rat kidney proximal and thin limb segments [33]. The functional correlation for the closely aligned junctional elements which seem to predominate in secretory epithelia remains to be elucidated. Although clearly speculative, such an arrangement might contribute to the structural stability of the tortuous apices of the secretory cells while facilitating paracellular ionic diffusion, possibly by alignment of cation-selective junctional pores.

This research was supported by United States Public Health Service Research Grant AM 27559. Stephen A. Ernst is a recipient of United States Public Health Service Research Career Development Award 5K04 GM 00473. The authors are grateful to Dr. Robert Bolender for his suggestions and encouragement with regard to the morphometric analysis of junctional tortuosity and to Dr. Donald DiBona for critical comments concerning this manuscript.

\section{References}

1. Bulger, R.E. 1963. The structure of the rectal (salt-secreting) gland of the spiny dogfish, Squalus acanthias. Anat. Rec. 147: 95

2. Bulger, R.E. 1965. Electron microscopy of the stratified epithelium lining the excretory canal of the dogfish rectal gland. Anat. Rec. 151:589

3. Burger, J.W. 1962. Further studies on the function of the rectal gland in the spiny dogfish. Physiol. Zool. 35:205

4. Burger, J.W. 1972. Rectal gland secretion in the stingray, $D a-$ syatis sabira. Comp. Biochem. Physiol. 42 A:31

5. Burger, J.W., Hess, W.N. 1960. Function of the rectal gland in the spiny dogfish. Science 131:670

6. Choi, J.K. 1963. The fine structure of the urinary bladder of the toad, Bufo marinus. J. Cell Biol. 16:53

7. Claude, P. 1978. Morphological factors influencing transepithelial permeability: A model for the resistance of the zonula occludens. J. Membrane Biol. 39:219

8. Clande, P., Goodenough, D.A. 1973. Fracture faces of zonulae occludentes from "tight" and "leaky" epithelia. J. Cell Biol. 58:390

9. Degnan, K.J., Zadunaisky, J.A. 1977. Open-circuit $\mathrm{Na}^{+}$and $\mathrm{Cl}^{-}$fluxes across isolated opercular epithelia from seawateradapted Fundulus heteroclitus and the influence of adrenergic stimulators. Bull. Mt. Desert Ist. Biol. Lab. 17:68

10. Degnan, K.J., Zadunaisky, J.A. 1979. Open-circuit $\mathrm{Na}^{+}$and
$\mathrm{Cl}^{-}$fluxes across isolated opercular epithelia from the teleost, Fundulus heteroclitus. J. Physiol. (London) 294:483

1l. Degnan, K.J., Zadunaisky, J.A. 1980. Passive sodium movements across the opercular epithelium: The paracellular shunt pathway and ionic conductance. J. Membrane Biol. 55:175

12. Diamond, J.M. 1979. Channels in epithelial cell membranes and junctions. Fed. Proc. 37:2639

13. Diamond, J.M. 1978. Osmotic water flow in leaky epithelia. J. Membrane Biol. 51:195

14. DiBona, D.R., Mills, J.W. 1979. Distribution of $\mathrm{Na}^{+}$-pump sites in transporting epithelia. Fed. Proc. 38:134

15. Doyle, W.L. 1962. Tubule cells of the rectal salt-gland of Urolophus. Am. J. Anat, 111:223

16. Ellis, R.A., Goertemiller, C.C., Jr., Stetson, D.L. 1977. Significance of extensive "leaky" cell junctions in the avian salt gland. Nature (London) 265:555

17. Ernst, S.A., Dodson, W.B., Karnaky, K.J., Jr. 1980. Structural diversity of occluding junctions in the low-resistance chloridesecreting opercular epithelium of seawater-adapted killifish (Fundulus heteroclitus). J. Cell Biol. 87:488

18. Ernst, S.A., Hootman, S.R., Schreiber, J.H., Riddle, C.V. 1979. Structure of occluding junctions in the salt secreting epithelium of elasmobranch rectal gland. J. Cell Biol. 83:83a

19. Ernst, S.A., Milis, J.W. 1977. Basolateral plasma membrane localization of ouabain-sensitive sodium transport sites in the secretory epithelium of the avian salt gland. J. Cell Biol. 75:74

20. Ernst, S.A., Riddle, C. V., Karnaky, K.J., Jr. 1980. Relationship between localization of $\mathrm{Na}^{+}-\mathrm{K}^{+}$-ATPase, cellular fine structure and reabsorptive and secretory electrolyte transport. In: Current Topics in Membranes and Transport, Vol. 13. Cellular Mechanisms of Renal Tubular Ion-Transport. E.L. Boulpaep, editor. p. 335. Academic Press, New York

21. Eveloff, J., Karnaky, K.J., Jr., Silva, P., Epstein, F.H., Kinter, W.B. 1979. Elasmobranch rectal gland cells. Autoradiographic localization of $\left[{ }^{3} \mathrm{H}\right]$ ouabain-sensitive $\mathrm{Na}, \mathrm{K}$-ATPase in rectal gland of dogfish squalus acanthias. $J$. Cell Biol. 83:16

22. Eveloff, J., Kinne, R., Kinne-Saffran, E., Murer, H., Silva, P., Epstein, F.H., Stoff, J., Kinter., W. B. 1978. Coupled sodium and chloride transport into plasma membrane vesicles prepared from dogfish rectal gland. Pfluegers Arch. Eur. J. Physiol. 378: 87

23. Forster, R.P., Goldstein, L. 1976. Intracellular osmoregulatory role of amino acids and urea in marine elasmobranchs. Am. J. Physiol. 230:925

24. Frizzell, R.H., Field, M., Schultz, S.G. 1979. Sodium-coupled chloride transport by epithelial tissues. Am. J. Physiol. 236:F 1

25. Fromter, E., Diamond, J. 1972. Route of passive ion permeation in epithelia. Nature New Biol. 235:9

26. Goertemiller, C.C., Jr., Ellis, R.A. 1976. Localization of ouabain-sensitive, potassium-dependent nitrophenyl phosphatase in the rectal gland of the spiny dogfish, Squalus acanthias. Cell Tissue Res. 175:112

27. Hayslett, J.P., Schon, D.A., Epstein, M., Hogben, C.A.M. 1974. In vitro perfusion of the dogfish rectal gland. $A m J$. Physiol. 226: 1188

28. Karnovsky, M.J. 1971. Use of ferrocyanide-reduced osmium tetroxide in electron microscopy. Proc. 11th Annu. Meet. Am. Soc. Cell Biol. (New Orleans) p. 146

29. Machen, R.E., Erlij, D., Wooding, F.B.P. 1972. Permeable junctional complexes. The movement of lanthanum across rabbit gallbladder and intestine. J. Cell Biol. 54:302

30. Martinez-Palomo, A., Erlij, D. 1975. Structure of tight junctions in epithelia with different permeability. Proc. Nat. Acad. Sci. USA 72:4487

31. Mayhew, T.M. 1979. Basic stereological relationships for quantitative microscopical anatomy - a simple systematic approach. J. Anat. 129:95 
32. Moreno, J.H. 1975. Blockage of gallbladder tight junction cation-selective channels by 2,4,6-triaminopyrimidinium (TAP). J. Gen. Physiol. 66:97

33. Pricam, C., Humbert, F., Perrelet, A., Orci, L. 1974. A freezeetch study of the tight junctions of the rat kidney tubules. Lab. Invest. 30:286

34. Riddle, C.V., Ernst, S.A. 1979. Structural simplicity of the zonula occludens in the electrolyte secreting epithelium of the avian salt gland. J. Membrane Biol, 45:21

35. Sardet, C., Pisam, M., Maetz, J. 1979. The surface epithelium of teleostean fish gills. Cellular and junctional adaptations of the chloride cell in relation to salt adaptation. J. Cell Biol. 80:96

36. Siegel, N.J., Schon, D.A., Hayslett, J.P. 1976. Evidence for active chloride transport in dogfish rectal gland. Am.J. Physiol. 230: 1250

37. Siegel, N.J., Silva, P., Epstein, F.H., Maren, T.H. Hayslett, J.P. 1975. Functional correlates of the dogfish rectal gland during in vitro perfusion. Comp. Biochem. Physiol. 51 A:593

38. Silva, P., Solomon, R., Spokes, K., Epstein, F.H. 1977. Ouabain inhibition of gill Na-K-ATPase: Relationship to active chloride transport. J. Exp. Zool. 199:419

39. Silva, P., Stoff, J., Field, M., Fine, L. 1977. Mechanism of active chloride secretion by shark rectal gland: Role of Na-KATPase in chloride transport. Am. J. Physiol. 233:F 298

40. Smith, H.W. 1936. The retention and physiological role of urea in the elasmobranchii. Biol. Rev. 11:49
41. Stoff, J.S., Rosa, R., Hallac, R., Silva, P., Epstein, F.H. 1979. Hormonal regulation of active chloride transport in the dogfish rectal gland. Am. J. Physiol. 237:F 138

42. Stoff, J.S., Silva, P., Field, M., Forrest, J., Stevens, A., Epstein, F.H. 1977. Cyclic AMP regulation of active chloride transport in the rectal gland of marine elasmobranchs. J. Exp. Zool. 199: 443

43. Tisher, C.C., Yarger, W.E. 1975. Lanthanum permeability of tight junctions along the collecting duct of the rat. Kidney Int. $7: 35$

44. Van Lennep, E.W. 1968. Electron microscopic histochemical studies on salt-excreting glands in elasmobranchs and marine catfish. J. Ultrastruct. Res. 25:94

45. Weibel, E.R., Bolender, R.P. 1973. Stereological techniques for electron microscopic morphometry. In: Principles and Techniques of Electron Microscopy: Biological Applications. M.A. Hayat, editor. Vol. 3, p. 237. Van Nostrand Reinhold Co., New York

46. Welling, L.W., Welling, D.J. 1976. Shape of epithelial cells and intercellular channels in the rabbit proximal nephron. Kidney Int. 9:385

47. Whittembury, G., Rawlins, F.A. 1971. Evidence of a paracellular pathway for ion flow in the kidney proximal tubule: Electron microscopic demonstration of lanthanum precipitate in the tight junction. Pfluegers Arch. Eur. J. Physiol. 330:302

Received 5 May 1980; revised 15 September 1980 